\title{
Efeito da suplementação com sulfato de zinco ou propilenoglicol em ovinos em uma pastagem nativa da Caatinga no período chuvoso: desempenho, características da carcaça e da carne
}

\author{
[Effect of supplementation with either Zinc sulfate or propylene glycol in lambs on a native Caatinga \\ pasture in the wet season: performance, carcass and meat characteristics] \\ H.H.A. Costa ${ }^{1}$, E.O.S. Saliba ${ }^{1}$, D.B. Galvani ${ }^{2}$, A.V. Landim ${ }^{3}$, L.D. Lima ${ }^{2}$, A.L.C.C. Borges ${ }^{1}$, \\ M.A.D. Bomfim ${ }^{2}$, I. Borges ${ }^{3}$, F.A. Silva ${ }^{1}$ \\ ${ }^{1}$ Universidade Federal de Minas Gerais - Belo Horizonte, MG \\ ${ }^{2}$ Embrapa Caprinos e Ovinos - Sobral, CE \\ ${ }^{3}$ Universidade Estadual Vale do Acaraú - Sobral, CE
}

\begin{abstract}
RESUMO
Objetivou-se avaliar os efeitos do zinco ou do propilenoglicol sobre o desempenho e nas características da carcaça e da carne de ovinos sob pastejo em pastagem nativa da Caatinga. Utilizaram-se 24 ovinos, mestiços Santa Inês, machos, não castrados, peso inicial de 19,3 $\pm 2,52 \mathrm{~kg}$, com quatro meses de idade, oito repetições por tratamento, distribuídos em um delineamento inteiramente ao acaso. Os tratamentos foram: sem aditivo, controle $(\mathrm{CT})$, adição de sulfato de zinco $\left(\mathrm{ZnSO}_{4} \cdot 7 \mathrm{H}_{2} \mathrm{O}\right)(\mathrm{Zn})$ para fornecimento de $300 \mathrm{mg}$ de $\mathrm{Zn}$ dia $^{-1}$ via sal mineral, e propilenoglicol (PG), 2,5mL $\mathrm{kgPC}^{0,75-1} \mathrm{animal}^{-1} \mathrm{dia}^{-1}$ misturado no concentrado. Os animais foram suplementados com concentrado constituído de milho (54,0\%), farelo de soja $(45,1 \%)$ e calcário $(0,911 \%)$ em $0,7 \%$ do PC médio de cada tratamento. $\mathrm{O}$ ensaio foi conduzido durante quatro meses (março a junho/2014). Avaliaram-se o desempenho e, após o abate dos animais, as características de carcaça e os componentes não carcaça, os parâmetros físico-químicos e organolépticos na carne. $\mathrm{O} \mathrm{Zn}$ e o propilenoglicol não afetaram o desempenho e os parâmetros da carcaça em termos absoluto e relativo, bem como os pesos dos cortes e seus rendimentos ( $\mathrm{P}>0,05)$. Não houve efeito dos aditivos nas características organolépticas e nos aspectos físico-químicos da carne $(\mathrm{P}>0,05)$, exceto cinzas $(\mathrm{P}<0,05)$. $\mathrm{O}$ zinco e o propilenoglicol não melhoram o desempenho e as características da carcaça de animais terminados em pastagem nativa da Caatinga. $\mathrm{O}$ baixo suprimento energético devido à má qualidade do pasto entre os meses de abril a junho contribui para a ineficiência no aproveitamento dos constituintes proteicos, implicando menor consumo e consequente diminuição do desempenho.
\end{abstract}

Palavras-chave: fermentação ruminal, pasto nativo, semiárido, zinco

\begin{abstract}
The aim was to evaluate the effects of zinc sulfate or propylene glycol on performance and carcass and meat characteristics from sheep under grazing in native Caatinga (Brazilian savannah) pasture during the rainy season. Twenty-four intact Santa Ines crossbreed male lambs, with an initial weight of $19.3 \pm 2.52 \mathrm{~kg}$, and 4-mo old, were distributed in a completely randomized design with eight replications per treatment. The treatments were composed of additives, as follows: no additive - control (CT); addition of zinc sulfate $\left(\mathrm{ZnSO}_{4} \cdot 7 \mathrm{H}_{2} \mathrm{O}\right)(\mathrm{Zn})$ to supply a total of $300 \mathrm{mg} \mathrm{Zn}$ day ${ }^{-1}$ on mineral salt; and addition of propylene glycol $(P G), 2.5 \mathrm{~mL} \mathrm{~kg} \mathrm{LW^{0.75-1 }}$ animal ${ }^{-1}$ day ${ }^{-1}$ mixed directly in the concentrate. Afterwards, they were supplemented with concentrate at $0.7 \%$ of the average $L W$ of each batch according to the treatments. The concentrate was based on corn (54.0\%), soybean meal (45.1\%), and limestone (0.911\%). The trials were carried out during the rainy season (March to June 2014), and evaluated the performance, and before of slaughter, carcass characteristics and non-carcass components were
\end{abstract}

Recebido em 7 de março de 2016

Aceito em 31 de maio de 2017

E-mail: helioa.costa@gmail.com 
evaluated and the physical-chemical aspects and the organoleptic attributes on the meat. The additives did not affect the performance, parameters of carcass, in terms absolute and relative, carcass morphometric measurements, weight of the commercial cuts and yields $(P>0.05)$. The additives did not affect the organoleptic characteristics and physical-chemical aspects of the meat (P>0.05), except, ash $(P<0.05)$. The zinc sulfate and propylene glycol did not improve on performance and in carcass characteristics in lambs finished on a native Caatinga (Brazilian savannah) pasture. The low supply energetic due to poor quality of pasture between the months of April to June, which contributed to inefficiency in the utilization of proteics constituents, implying in lower intake, and decrease in performance.

Keywords: native pasture, rumen fermentation, semi-arid, zinc

\section{INTRODUÇÃO}

O bioma Caatinga é caracterizado pela diversidade de espécies forrageiras nos diferentes estratos, herbáceo, arbustivo e arbóreo. Por ser a vegetação predominante do semiárido do Nordeste brasileiro, $70 \%$ das espécies contidas nesse bioma constituem a fração dietética dos ruminantes domésticos. A alimentação de pequenos ruminantes, por sua vez, no semiárido normalmente é caracterizada pela sazonalidade na produção de forragem ao longo do ano. As chuvas são concentradas em um curto período do ano, janeiro a maio (Pfister e Malecheck, 1986), e a disponibilidade e a qualidade da forragem são comprometidas ao final desse período e durante todo o período seco.

Estudos recentes indicaram que a suplementação com fontes de $\mathrm{Zn}$ acima da exigência, respeitando-se a concentração tolerável ao animal, pode alterar a fermentação ruminal, com influência direta no metabolismo intermediário e no controle endócrino nos animais. Os mecanismos de ação consistem na maior captura de energia alimentar com ação direta na produção de ácidos graxos voláteis, o que eleva a proporção do propionato, e traz efeitos positivos no rúmen, sendo via competitiva de uso de $\mathrm{H}_{2}$ e minimizando perdas energéticas na forma de metano (Arelovich et al., 2000; Eryavuz e Dehority, 2009). Além disso, um maior teor de $\mathrm{Zn}$ dietético influencia no metabolismo de glicose sanguínea e em sua regulação pela insulina em ovinos. Esses aspectos podem implicar ganhos em termos produtivos (i.e., ganho de peso), uma vez que esses processos fisiológicos estão relacionados ao crescimento e ao balanço de energia com consequente eficiência de uso da energia dos alimentos (Jafarpour et al., 2015).
O fornecimento de propilenoglicol (PG) aumenta a concentração de propionato no rúmen, de forma indireta, mediante a formação de lactato, que, em seguida pode ser convertido em glicose (Kim et al., 2005). A fermentação do PG no rúmen caracteriza-se ainda por produzir $\mathrm{CO}_{2} \mathrm{e}$ inibição significativa da produção de metano, implicando menor perda de energia (Czerkawski e Brekckerindge, 1973), que pode ser utilizada para elevar a produção de carne por animal e área.

Portanto, o incremento na suplementação dietética de ovinos via fornecimento de alimentos concentrados e/ou aditivos, sob condições semiáridas, visa elevar o consumo e o aproveitamento dos nutrientes contidos no pasto. Possibilita também a obtenção de carcaças mais pesadas, com melhores rendimentos de carcaça e dos cortes cárneos, e melhorias nas características da carne (Dantas et al., 2008). A hipótese aqui levantada é a de que as suplementações com sulfato de zinco e propilenoglicol para ovinos em pastagem nativa propiciam melhorias na eficiência de aproveitamento dos nutrientes, e.g. proteínas, e diminuição na perda energética, sendo essa energia direcionada para atender as exigências de manutenção e aquelas voltadas à atividade de pastejo e produção. Objetivou-se, com o presente estudo, avaliar os efeitos do zinco ou do propilenoglicol sobre o desempenho e as características da carne de ovinos sob pastejo, em uma pastagem nativa da Caatinga, durante o período chuvoso.

\section{MATERIAL E MÉTODOS}

Todos os procedimentos e o manuseio dos animais experimentais foram realizados de acordo com os protocolos aprovados pelo Comitê de Ética no Uso de Animais da Universidade 
Federal de Minas Gerais (Ceua/UFMG, $n^{\circ} 321 / 2013$ ).

A pesquisa foi conduzida na Embrapa Caprinos e Ovinos, Sobral, Ceará, no Nordeste do Brasil, $3^{\circ} 45^{\prime} 51.59^{\prime \prime} \mathrm{S}$ e $40^{\circ} 21^{\prime} 04.24^{\prime \prime} \mathrm{O}$, a $92 \mathrm{~m}$ de altitude acima do nível do mar. Foram utilizados oito hectares de uma área de pastagem nativa da Caatinga, manipulada por meio de raleamento conforme Silva et al. (2007). Os solos dominantes na área foram os litólicos distróficos, planossolos e brunos não cálcicos. Os ensaios foram realizados no período chuvoso (março a junho/2014), com precipitação de $514 \mathrm{~mm}$, temperatura e umidade relativa do ar média de $26,5^{\circ} \mathrm{C}$ e $78,0 \%$, respectivamente (Banco..., 2015).

\begin{abstract}
Antes do início experimental, foram determinadas as ocorrências dos principais grupos e espécies forrageiras, pelo método de ranqueamento, avaliando-se a frequência das espécies herbáceas e a disponibilidade de matéria seca (MS), conforme metodologia descrita por Araújo Filho (2013). Para estimativa da disponibilidade de forragem em peso, foi realizada a coleta da forragem do estrato herbáceo contido dentro do perímetro do quadrante a cada $12 \mathrm{~m}$. O material foi pesado logo em seguida à amostragem e pré-seco em estufa a $55^{\circ} \mathrm{C}$ por 72 horas, sendo novamente pesado para se determinar a disponibilidade de MS ha $^{-1}$, conforme recomendação de Araújo Filho (2013) (Tab. 1).
\end{abstract}

Tabela 1. Disponibilidade do estrato herbáceo, expresso em MS, e composição florística da pastagem nativa da Caatinga no período chuvoso

\begin{tabular}{|c|c|c|c|c|}
\hline \multicolumn{3}{|c|}{ Disponibilidade de MS kg ha ${ }^{-1}$} & \multicolumn{2}{|c|}{ Composição florística, \% } \\
\hline Leguminosas & Gramíneas & Total & Leguminosas & Gramíneas \\
\hline 1364 & 533 & 1897 & 71,9 & 28,1 \\
\hline
\end{tabular}

Os tratamentos foram: sem aditivo, controle $(\mathrm{CT})$, adição de sulfato de zinco $\left(\mathrm{ZnSO}_{4} \cdot 7 \mathrm{H}_{2} \mathrm{O}\right)$, (Zn) com disponibilidade de $22,5 \%$ de $\mathrm{Zn}$, e adição de propilenoglicol (Lote 55065-USP) (PG), durante quatro meses de avaliações do desempenho. Ao final desse período, realizou-se $\mathrm{o}$ abate dos animais.

Foi fornecido sal mineral para ovinos em todos os tratamentos, e sua composição, conforme o fabricante, foi: $\mathrm{Ca}=82,0 \mathrm{~g}, \mathrm{Co}=30,0 \mathrm{mg}, \mathrm{Cu}=$ $350 \mathrm{mg}, \mathrm{Cr}=11,7 \mathrm{mg}, \mathrm{S}=11,7 \mathrm{~g}, \mathrm{P}=60,0 \mathrm{~g}, \mathrm{I}=$ $50,0 \mathrm{mg}, \mathrm{Mn}=1200 \mathrm{mg}, \mathrm{Mo}=180 \mathrm{mg}, \mathrm{Se}=15 \mathrm{mg}$, $\mathrm{Na}=132 \mathrm{~g}$ e $\mathrm{Zn}=2600 \mathrm{mg}$, por $\mathrm{kg}$ de produto, para todos os tratamentos. A quantidade inicial de sal fornecida para todos os animais foi $30 \mathrm{~g}$ animal $^{-1}$ dia $^{-1}$, realizando-se ajuste baseado nas sobras diárias. Para fornecimento de $\mathrm{Zn}$, foram adotados os procedimentos descritos por Arelovich et al. (2000) e o nível máximo de toxidez tolerável para ovinos conforme o NRC (Mineral..., 2005), em que foram fornecidos $300 \mathrm{mg}$ de $\mathrm{Zn} \mathrm{dia}^{-1}$, sendo a quantidade estabelecida considerando-se a concentração de $\mathrm{Zn}$ no sal mineral e, nesse acrescido,
$\mathrm{ZnSO}_{4} .7 \mathrm{H}_{2} \mathrm{O}$, sendo o $\mathrm{Zn}$ fornecido via sal mineral. O PG foi fornecido em $2,5 \mathrm{~mL} \mathrm{kgPC}^{0,75-1}$ animal $^{-1} \operatorname{dia}^{-1}$ (Kim et al., 2005), misturados diretamente no concentrado. $\mathrm{O}$ ajuste do $\mathrm{PG}$ foi realizado semanalmente, de acordo com o peso médio em $\mathrm{kg} \mathrm{PC}^{0,75}$ do grupo $(\mathrm{n}=8)$.

Foram utilizados 24 ovinos, mestiços Santa Inês, machos, não castrados, peso inicial 19,3 $\pm 2,52 \mathrm{~kg}$, quatro meses de idade, com oito repetições por tratamento, distribuídos em um delineamento inteiramente ao acaso. Os animais foram mantidos em lotação contínua e pesados semanalmente para acompanhamento do ganho de peso diário e ajuste da suplementação.

Foi adotada taxa de lotação fixa de 0,4 ha cabeça ${ }^{1}$, considerando-se animal de $30 \mathrm{~kg}$ de PC (Araújo Filho, 1990). Os animais foram direcionados para o pasto às sete horas e recolhidos ao aprisco às $16 \mathrm{~h}$. Foram divididos em baias coletivas conforme os tratamentos e suplementados com concentrado em $0,7 \%$ do PC médio de cada lote de acordo com os diferentes tratamentos, sem sobras no cocho. O concentrado foi à base de 
milho, farelo de soja e calcário, formulado conforme recomendações do NRC (Nutrient..., 2007), para categoria de terminação e previsão de ganho de peso médio de $150 \mathrm{~g} \mathrm{dia}^{-1}$.

Dois animais canulados no rúmen foram usados para coleta de extrusa ruminal para obtenção de amostras mais fidedignas do pasto, sendo coletadas mensalmente conforme descrito por Olson (1991). A coleta de extrusa foi realizada por cinco dias, iniciando-se um dia antes da coleta de fezes nos animais utilizados para se determinar o consumo (Tab. 2).

Tabela 2. Composição do concentrado e da extrusa ruminal ${ }^{\dagger}$ coletada em ovinos, obtida em pastagem nativa da Caatinga no período chuvoso

\begin{tabular}{cccccc}
\hline \multirow{2}{*}{ Variáveis } & \multicolumn{5}{c}{ Períodos } \\
\cline { 2 - 5 } & Março & Abril & Maio & Junho & Concentrado $^{\beta}$ \\
\hline MS, ${ }^{\ddagger} \%$ & 11,8 & 12,8 & 14,2 & 15,8 & 87,7 \\
\% & & & & & \\
MO & 81,9 & 81,0 & 79,8 & 81,9 & 91,3 \\
PB & 19,2 & 18,7 & 17,6 & 13,1 & 25,4 \\
NIDN & 5,64 & 4,98 & 4,60 & 3,73 & 20,3 \\
NIDN, \% do nitrogênio total & 51,8 & 56,7 & 59,8 & 52,9 & 17,5 \\
Extrato etéreo & 7,60 & 7,65 & 8,68 & 11,1 & 6,40 \\
FDN & 59,8 & 65,6 & 67,5 & 61,7 & 13,7 \\
FDNcp & 49,4 & 56,1 & 58,2 & 52,6 & 10,9 \\
FDA & 49,0 & 53,2 & 53,7 & 51,4 & 12,1 \\
Hemiceluloses & 10,7 & 12,7 & 13,8 & 9,40 & 6,49 \\
Celulose & 25,3 & 24,9 & 24,7 & 24,9 & 5,32 \\
Lignina Klason & 36,2 & 38,9 & 37,1 & 40,7 & 4,10 \\
DIVMS & 53,7 & 40,8 & 42,4 & 44,1 & 95,4 \\
DIVMO & 46,8 & 33,3 & 35,3 & 35,9 & 93,9 \\
\hline
\end{tabular}

†Extrusas coletadas com prévio esvaziamento do rúmen após uma hora de pastejo em área de Caatinga raleada; ${ }^{\beta}$ milho, farelo de soja e calcário; ${ }^{\ddagger}$ matéria seca em base de matéria natural; ${ }^{\ddagger}$ FDNcp = FDN corrigido para cinzas e proteína; ${ }^{\dagger}$ conforme Tilley e Terry (1963).

O consumo total de $\mathrm{MO}$ (CMO) foi calculado usando-se a produção de MS fecal estimada por meio de indicador $\operatorname{LIPE}^{\circledR}$ (Saliba et al., 2016). A digestibilidade considerada na equação foi a DIVMO (Tilley e Terry, 1963). Para corrigir a contaminação por minerais via saliva nas amostras de extrusas coletadas do pasto, o consumo foi expresso realizando-se a correção para MO (Wallace et al., 1972).

As análises químico-bromatológicas foram realizadas no Laboratório de Nutrição Animal da Embrapa Caprinos e Ovinos. Amostras das espécies forrageiras, extrusas e fezes foram présecas a $55^{\circ} \mathrm{C}$ por 72 horas e, juntamente com o concentrado, foram moídas em moinho de facas dotado de peneiras de $1 \mathrm{~mm}$. Foram analisadas para matéria seca (MS; método 934.01), cinzas (método; 938.08), proteína bruta (PB; método 968.06) em aparelho Leco ${ }^{\circledR}$ (CN628, St. Josesh, MI, EUA) e extrato etéreo (EE; método 920.39) conforme a AOAC (Official..., 1990). A MO foi calculada como a diferença entre a MS e o teor de cinzas. A fibra em detergente neutro (FDN) e a fibra em detergente ácido (FDA) foram analisadas segundo Van Soest et al. (1991), com adaptação para análise em autoclave conforme Senger et al. (2008). A lignina Klason (LK) foi analisada por meio de hidrólise ácida, de acordo com Hatifield et al. (1994), e os valores de nitrogênio insolúvel em detergente neutro (NIDN) conforme Licitra et al. (1996).

Foi realizado acompanhamento do desempenho ponderal dos ovinos, para obtenção de ganho de peso médio diário (GPMD, g) e ganho total (GPT, kg). Os animais foram abatidos após 112 dias de terminação, com peso corporal (PC) médio de $23,0 \mathrm{~kg}$, no fim do período chuvoso.

Previamente aos procedimentos de abate, os animais foram submetidos a jejum de dieta sólida por 16 horas. Após o jejum, foram pesados, sendo obtido o peso corporal ao abate (PCA). O abate foi realizado conforme as normas de regulamentação de inspeção industrial e sanitária 
de produtos de origem animal (Brasil, 1997). Após a evisceração, foram pesados os constituintes não carcaça. $\mathrm{O}$ peso do corpo vazio (PCVZ) foi determinado de acordo com Silva Sobrinho (2001). Na carcaça quente foi mensurado o $\mathrm{pH}$ inicial; em seguida, esta foi pesada e acondicionada em câmara fria, na temperatura de $4^{\circ} \mathrm{C}$, por 24 horas. Posteriormente, na carcaça fria foi mensurado o pH final, e, então, ela foi pesada.

Com base nos pesos das carcaças quente (PCQ) e fria (PCF), foram calculados os parâmetros relacionados às carcaças, tais como: rendimento da carcaça quente $(\mathrm{RCQ})=(\mathrm{PCQ} / \mathrm{PCA}) \times 100$; rendimento da carcaça fria $(\mathrm{RCF})=(\mathrm{PCF} / \mathrm{PCQ})$ $\mathrm{x} 100$; perda por resfriamento $(\mathrm{PR})=[(\mathrm{PCQ}-$ $\mathrm{PCF}) / \mathrm{PCQ}] \mathrm{x} 100$; e rendimento biológico verdadeiro $(R B V)=(P C Q / P C V Z) \times 100$.

Foram realizadas as medidas de conformação (Cezar e Sousa, 2007) e morfometria da carcaça (Osório et al., 1998). Foi calculado o índice de compacidade da carcaça (ICC) = $\mathrm{PCF} /$ comprimento interno da carcaça. Em seguida, a carcaça foi seccionada longitudinalmente e a hemicarcaça esquerda, pesada. Realizaram-se os cortes comerciais, os quais foram pesados, e determinaram-se os rendimentos em relação ao peso da hemicarcaça reconstituída (Silva Sobrinho, 2001).

No músculo longissimus dorsi, na altura da $12^{\mathrm{a}}$ vértebra torácica, foi calculada a área de olho de lombo (AOL) pelo padrão gabarito transparente quadriculado, $1 \mathrm{~mm}^{2}$ célula $^{-1}$ (Cunha et al., 2001), e, com o uso de paquímetro digital mensurado, a espessura de gordura subcutânea (EGS). Da amostra do músculo longissimus dorsi foram extraídas quatro subamostras de $2,5 \mathrm{~cm}$ de espessura, as quais foram identificadas, embaladas individualmente e acondicionadas em freezer com temperatura a $-20^{\circ} \mathrm{C}$, para posteriores avaliações quantitativas e qualitativas da carne.

$\mathrm{Na}$ carne, foram determinados os teores de umidade (método 950.46), cinzas (método 920.153) e proteína (método 984.13) de acordo com a AOAC (Official..., 1990). Os lipídios totais foram determinados com clorofórmio e metanol 2:1 (Folch et al., 1957); a capacidade de retenção de água por pressão, conforme Sierra (1973); a perda de peso por cocção, segundo Duckett et al. (1998). Após a cocção, foi determinada a força de cisalhamento em texturômetro Warner-Bratzler-Shear (Wheeler et al., 1996). A análise sensorial foi determinada pelo teste da escala hedônica (Larmond, 1979), sendo avaliados parâmetros sensoriais de dureza, suculência, sabor, aroma e aceitação global.

Para avaliação do desempenho e das características de carcaça e da carne, foi utilizado delineamento inteiramente ao acaso. As diferenças estatísticas dos parâmetros nos tratamentos foram determinadas utilizando-se o seguinte modelo estatístico:

$Y_{i j k}=\mu+T_{i}+a_{i j}+e_{i j k}$,

em que: $\mu=$ média geral; $\mathrm{T}_{\mathrm{i}}=$ efeito fixo dos tratamentos $\left(\mathrm{i}=\mathrm{CT}\right.$; Zn; PG); $\mathrm{a}_{\mathrm{ij}}=$ efeito residual aleatório associado ao animal; $\mathrm{e}_{\mathrm{ijk}}=$ erro experimental associado à observação. As médias foram comparadas por meio do teste de TukeyKramer, admitindo-se significância de 0,05. Para variáveis, conformação e acabamento e atributos organolépticos, utilizou-se o teste de KruskalWallis. Empregou-se o procedimento Proc GLM do Statistical Analysis System - SAS ${ }^{\circledR}$ 9.0.

\section{RESULTADOS E DISCUSSÃO}

A composição das espécies do estrato herbáceo foi de $28,0 \%$ de gramíneas e, em maior parte, de leguminosas, $72,0 \%$ (Tab. 1). $\mathrm{A}$ área de pastagem no início do estudo apresentou disponibilidade de MS total do estrato herbáceo de $1897 \mathrm{~kg}$ hectare ${ }^{-1}$, sendo favorecidos pela boa média de precipitação de chuvas nos primeiros meses do período chuvoso. Foram obtidos, para composição do pasto, valores de proteína bruta $(19,1 \%$ a $13,1 \%)$ e digestibilidade da matéria orgânica $(46,8 \%$ e $35,9 \%$ ), no início (março) e no final do período chuvoso (junho), respectivamente (Tab. 2). O sulfato de zinco e o propilenoglicol não afetaram o desempenho e os parâmetros da carcaça $(\mathrm{P}>0,05$; Tab. 3). 
Tabela 3. Efeito do sulfato de zinco e do propilenoglicol no desempenho e nas características da carcaça em ovinos, em pastagem nativa da Caatinga, no período chuvoso

\begin{tabular}{|c|c|c|c|c|c|}
\hline \multirow{2}{*}{ Variáveis } & \multicolumn{3}{|c|}{ Aditivos $^{+}$} & \multirow{2}{*}{ Valor-P } & \multirow{2}{*}{$\mathrm{EPM}^{\ddagger}$} \\
\hline & $\mathrm{CT}$ & $\mathrm{Zn}$ & PG & & \\
\hline \multicolumn{6}{|c|}{ Desempenho, kg } \\
\hline Consumo matéria orgânica & 0,527 & 0,542 & 0,551 & 0,482 & 0,009 \\
\hline Ganho de peso médio diário & 0,041 & 0,042 & 0,049 & 0,659 & 0,003 \\
\hline Ganho de peso total & 4,59 & 4,75 & 5,52 & 0,659 & 0,324 \\
\hline Peso vivo ao abate & 22,4 & 23,6 & 22,5 & 0,706 & 0,660 \\
\hline \multicolumn{6}{|c|}{ Carcaça, kg } \\
\hline Peso do corpo vazio & 13,2 & 14,2 & 14,0 & 0,596 & 0,430 \\
\hline Carcaça quente & 7,51 & 7,95 & 8,02 & 0,740 & 0,269 \\
\hline Carcaça fria & 7,36 & 7,84 & 7,85 & 0,717 & 0,267 \\
\hline \multicolumn{6}{|c|}{ Rendimentos, $\%$} \\
\hline Carcaça quente & 33,5 & 33,7 & 35,4 & 0,140 & 0,403 \\
\hline Carcaça fria & 32,8 & 33,2 & 34,7 & 0,173 & 0,403 \\
\hline Biológico verdadeiro & 56,9 & 55,9 & 57,1 & 0,443 & 0,449 \\
\hline Perda por resfriamento & 1,59 & 1,38 & 1,84 & 0,523 & 0,143 \\
\hline
\end{tabular}

${ }^{a}$ Médias na mesma linha seguidas por letras distintas são diferentes pelo teste de Tukey-Kramer $(\mathrm{P}<0,05)$.

${ }^{\ddagger} \mathrm{CT}=$ sem aditivo; $\mathrm{Zn}=$ adição de $\mathrm{ZnSO}_{4} \cdot 7 \mathrm{H}_{2} \mathrm{O}$ para fornecimento de $300 \mathrm{mg} \mathrm{Zn}$ dia ${ }^{-1}$ no sal; $\mathrm{PG}=$ adição de $2,5 \mathrm{~mL}$ $\mathrm{kgPC}^{0,75-1}$ animal $^{-1} \mathrm{dia}^{-1}$ de propilenoglicol misturado ao concentrado. ${ }^{¥} \mathrm{EPM}=$ erro-padrão da média.

Foi esperado, entretanto, que o suprimento de proteína oriundo do pasto da Caatinga favorecesse ganhos de peso mais elevados aos obtidos neste estudo, nos animais sob pastejo, fato não observado $(\mathrm{P}=0,659)$. Nesse sentido, houve uma diminuição nos teores de PB do pasto em $31,6 \%$ no último mês da terminação, em que a PB encontrava-se acima de 13\%. Contudo, características como a qualidade dessa proteína, em termos de disponibilidade para ataque microbiano, aliada à menor energia disponível no pasto, que diminuiu nos meses de abril a junho (DIVMO, < 36\%; Tab. 2), podem ter comprometido o consumo e o consequente ganho de peso desses animais (Tab. 3).

Em pastagens nativas do semiárido, a $\mathrm{PB}$ não é o fator limitante, mas $\mathrm{O}$ aporte de energia prontamente disponível, em muitos casos, parece ser o principal complicador, o que não favoreceu maior ingestão e aproveitamento dos nutrientes de forma eficiente.

Adicionalmente, a inclusão do sulfato de zinco e de propilenoglicol não implicou melhorias na eficiência de uso dos nutrientes dietéticos do pasto pelos animais que pudessem incrementar o ganho de peso diário $(0,044 \mathrm{~kg})$, o peso das carcaças quente e fria $(7,83$ e $7,68 \mathrm{~kg}$, respectivamente) e os rendimentos das carcaças quente e fria (34,2 e 33,6\%; Tab. 3). A adição de sulfato de zinco e de propileglicol não propiciou melhorias da fermentação que acarretassem consumo e consequente ganho de peso mais elevado.

Em pesquisa avaliando os efeitos do cruzamento com raças nativas e do tipo de dieta para cordeiros, sendo a base dietética feno de pasto nativo, no semiárido da Etiópia, foi obtido ganho de peso médio de $0,040 \mathrm{~kg}$ dia $^{-1}$, ao abate de $19,5 \mathrm{~kg}$ e das carcaças quente e fria de $8,50 \mathrm{e}$ $8,15 \mathrm{~kg}$, respectivamente (Tsegay et al., 2013).

Ao se acompanhar o comportamento dos parâmetros de carcaça, observou-se que não houve efeito da suplementação com sulfato de zinco e propilenoglicol para peso dos cortes comercias e seus rendimentos ( $\mathrm{P}>0,05$; Tab. 4). Os baixos índices nos parâmetros de desempenho e carcaça prejudicaram também os pesos dos cortes comerciais, associados ao baixo percentual de suplementação fornecido neste estudo (concentrado em $0,7 \%$ do $\mathrm{PC}$ ), aliado à não efetividade dos aditivos fornecidos. Concomitante a esses fatores, o desempenho foi afetado, pela disponibilidade e qualidade do pasto, mesmo sem diferenças para o $\mathrm{CMO}$ (Tab. 3). Suplementações estratégicas corrigindo as deficiências do pasto ao longo dos meses podem favorecer maiores ganhos de peso em ovinos terminados em pasto nativo da Caatinga. Em avaliações do desempenho de ovelhas em Caatinga raleada e enriquecida, suplementadas 
com quantidades distintas de concentrado, foi observado maior ganho de peso durante a lactação e ao desmame, assim como das crias com maior peso ao nascer e ao desmame, quando as ovelhas receberam $500 \mathrm{~g}$ de concentrado por dia (Araújo, 2015).

Tabela 4. Efeito do sulfato de zinco e do propilenoglicol em ovinos em pastagem nativa da Caatinga no período chuvoso, nos cortes comerciais e nos rendimentos

\begin{tabular}{|c|c|c|c|c|c|}
\hline \multirow{2}{*}{ Variáveis } & \multicolumn{3}{|c|}{ Aditivos } & \multirow{2}{*}{ Valor-P } & \multirow{2}{*}{$\mathrm{EPM}^{\ddagger}$} \\
\hline & $\mathrm{CT}$ & $\mathrm{Zn}$ & PG & & \\
\hline \multicolumn{6}{|c|}{ Pesos cortes, kg } \\
\hline Costela & 0,294 & 0,316 & 0,335 & 0,580 & 0,015 \\
\hline Lombo & 0,302 & 0,360 & 0,329 & 0,338 & 0,016 \\
\hline Paleta & 0,509 & 0,585 & 0,565 & 0,435 & 0,024 \\
\hline Pescoço & 0,381 & 0,351 & 0,379 & 0,665 & 0,015 \\
\hline Serrote & 0,910 & 0,976 & 0,964 & 0,742 & 0,036 \\
\hline Pernil & 1,20 & 1,24 & 1,24 & 0,944 & 0,053 \\
\hline \multicolumn{6}{|c|}{ Rendimentos cortes, $\%$} \\
\hline Costela & 8,13 & 8,32 & 8,90 & 0,524 & 0,287 \\
\hline Lombo & 8,22 & 9,46 & 8,68 & 0,150 & 0,256 \\
\hline Paleta & 14,1 & 15,2 & 15,0 & 0,465 & 0,371 \\
\hline Pescoço & 10,7 & 9,17 & 10,0 & 0,039 & 0,231 \\
\hline Serrote & 25,3 & 25,4 & 25,2 & 0,975 & 0,346 \\
\hline Pernil & 33,5 & 32,4 & 32,2 & 0,442 & 0,438 \\
\hline
\end{tabular}

${ }^{a}$ Médias na mesma linha seguidas por letras distintas são diferentes pelo teste de Tukey-Kramer $(\mathrm{P}<0,05)$.

${ }^{\sharp} \mathrm{CT}=$ ausência de aditivo; $\mathrm{Zn}=$ adição de $\mathrm{ZnSO}_{4} \cdot 7 \mathrm{H}_{2} \mathrm{O}$ para fornecimento de $300 \mathrm{mg} \mathrm{Zn} \mathrm{dia}{ }^{-1}$ no sal; $\mathrm{PG}=$ adição de $2,5 \mathrm{ml} \mathrm{kgPC}^{0,75-1}$ animal $^{-1} \mathrm{dia}^{-1}$ de propilenoglicol misturado ao concentrado. ${ }^{¥} \mathrm{EPM}=$ erro-padrão da média.

No último mês do período chuvoso, foi observado declínio nos teores de proteína e na digestibilidade da matéria orgânica, aliado à menor disponibilidade de espécies de maior predileção e à baixa qualidade da dieta ingerida, conforme observado no mês de junho, o que limitou o aproveitamento dos nutrientes. Portanto, para atingir ganhos de peso superiores, é recomendado realizar correções das deficiências de nutrientes oriundos do pasto com suplementações em níveis mais elevados em termos de energia e proteína. Em condições de pastejo em pasto da Caatinga, a fração energética parece ser o fator mais limitante para o aproveitamento dos compostos nitrogenados.

A morfometria da carcaça e as avaliações da AOL não foram afetadas pelo sulfato de zinco e o propilenoglicol $(\mathrm{P}>0,05)$, contudo foi verificada maior espessura de gordura para o tratamento $\mathrm{Zn}(\mathrm{P}<0,05$; Tab. 5).

A não alteração na morfometria e nos demais parâmetros de carcaça de ovinos em terminação pode estar relacionada à ineficiência da suplementação com sulfato de zinco e propilenoglicol em alterar o perfil fermentativo, além de incrementar maiores ganhos de massa muscular e deposição de gordura na carcaça. Em avaliações em bovinos de corte em crescimento suplementados com propilenoglicol, verificou-se incremento na disponibilidade de glicose no animal, contudo não foi um método capaz de aumentar a proporção de gordura intramuscular nas carcaças (Kim et al., 2005). 
Tabela 5. Efeito do sulfato de zinco e do propilenoglicol em ovinos em pastagem nativa da Caatinga no período chuvoso na morfometria da carcaça

\begin{tabular}{|c|c|c|c|c|c|}
\hline \multirow{2}{*}{ Variáveis } & \multicolumn{3}{|c|}{ Aditivos } & \multirow{2}{*}{ Valor-P } & \multirow{2}{*}{$\mathrm{EPM}^{*}$} \\
\hline & $\mathrm{CT}$ & $\mathrm{Zn}$ & PG & & \\
\hline \multicolumn{6}{|c|}{ Morfometria carcaça, cm } \\
\hline Comprimento da carcaça & 52,0 & 52,2 & 52,4 & 0,945 & 0,512 \\
\hline Perímetro torácico & 59,2 & 61,2 & 61,3 & 0,303 & 0,582 \\
\hline Perímetro da perna & 14,6 & 14,6 & 14,5 & 0,913 & 0,212 \\
\hline Comprimento da perna & 31,9 & 32,6 & 31,5 & 0,448 & 0,334 \\
\hline Comprimento interno da carcaça & 51,5 & 54,0 & 53,1 & 0,294 & 0,649 \\
\hline Profundidade da carcaça & 29,4 & 27,9 & 28,5 & 0,296 & 0,392 \\
\hline Largura da garupa & 13,3 & 13,6 & 13,8 & 0,683 & 0,210 \\
\hline Índice de compacidade da carcaça $\left(\mathrm{kg} \mathrm{cm}^{-1}\right)$ & 0,150 & 0,152 & 0,147 & 0,323 & 0,004 \\
\hline Conformação $(1-5)^{\beta, 1}$ & 1,93 & 1,64 & 1,42 & 0,423 & 0,111 \\
\hline Acabamento $(1-5)^{\beta, 2}$ & 1,93 & 2,29 & 1,71 & 0,376 & 0,127 \\
\hline Área de olho de lombo gabarito $\left(\mathrm{cm}^{2}\right)$ & 6,25 & 6,50 & 5,60 & 0,538 & 0,339 \\
\hline Espessura de gordura $(\mathrm{mm})$ & $0,359^{\mathrm{b}}$ & $0,635^{\mathrm{a}}$ & $0,490^{\mathrm{b}}$ & 0,016 & 0,036 \\
\hline
\end{tabular}

${ }^{a}$ Médias na mesma linha seguidas por letras distintas são diferentes pelo teste de Tukey-Kramer $(\mathrm{P}<0,05) \mathrm{e}^{\beta} \mathrm{Kruskal}^{-}$ Wallis. ${ }^{\ddagger} \mathrm{CT}=$ sem aditivo; $\mathrm{Zn}=$ adição de $\mathrm{ZnSO}_{4} \cdot 7 \mathrm{H}_{2} \mathrm{O}$ para fornecimento de $300 \mathrm{mg} \mathrm{Zn}$ dia ${ }^{-1}$ no sal; $\mathrm{PG}=$ adição de $2,5 \mathrm{ml} \mathrm{kgPC}^{0,75-1}$ animal $^{-1} \mathrm{dia}^{-1}$ de propilenoglicol misturado ao concentrado. ${ }^{¥} \mathrm{EPM}=$ erro-padrão da média.

Os animais nos diferentes tratamentos apresentaram pesos ao abate semelhantes, o que favoreceu para igualdade nas avaliações morfométricas. O baixo peso ao abate e o consequente menor peso da carcaça fria resultaram em baixo índice de compacidade, com média de $0,150 \mathrm{~kg} \mathrm{~cm}^{-1}$. Os animais foram abatidos com sete-oito meses de idade, com peso médio $23,0 \mathrm{~kg}$ de $\mathrm{PC}$ e AOL média de $6,11 \mathrm{~cm}^{2}$ (Tab. 5), fato que denota baixo desenvolvimento muscular, parte comercial mais valorizada, afetando as demais características de carcaça e cortes comerciais.

Ressalta-se que os parâmetros de $\mathrm{AOL}$ e de espessura de gordura também são utilizados como critérios para padronizar e classificar as carcaças em termos de conformação e acabamento nos grandes frigoríficos. Em pesquisa avaliando as características da carcaça de ovinos Santa Inês em pastejo na Caatinga, observou-se que, à medida que se elevaram os níveis de suplementação, houve maior índice de compacidade causado pela influência do maior peso da carcaça; por sua vez, não foi observada variação do comprimento em função da suplementação (Dantas et al., 2008).

Não houve diferença para peso dos componentes não carcaças $(\mathrm{P}>0,05)$, exceto para peso do sangue e dos rins $(\mathrm{P}<0,05 ;$ Tab. 6). Considerando-se somente os órgãos vermelhos, essa diferença representou $49,0 \%$ da fração que compõem os principais componentes não carcaças comestíveis e $32,8 \%$ do trato digestivo. Nas regiões semiáridas, a culinária utiliza-se dessas porções para confecção de pratos típicos, que são apreciados pela população local. O aproveitamento dos componentes não carcaças contribui para incremento dos valores obtidos por animal, por exemplo, pele, que pode representar de 10 a $12 \%$ no mercado do processamento de peles.

Os diferentes aditivos não afetaram as características organolépticas da carne e os aspectos físicos e químicos ( $\mathrm{P}>0,05 ; \mathrm{Tab}$. 7), exceto, para cinzas $(\mathrm{P}<0,05)$. $\mathrm{O}$ valor de $\mathrm{pH}$ após 24 horas $(5,85)$ foi adequado no período post mortem, decorrente da produção de ácido lático pela queima do glicogênio, propiciando adequado rigor mortis para transformação do músculo em carne, além de evitar proliferação de microrganismos indesejáveis que afetam a qualidade da carne (Lawrie, 2005). Os valores médios obtidos para capacidade de retenção de água (CRA) e perda por cocção (PPC) foram 58,15 e 53,9\%, respectivamente (Tab. 7). 
Efeito da suplementação...

Tabela 6. Efeito do sulfato de zinco e do propilenoglicol em ovinos em pastagem nativa da Caatinga, no período chuvoso, nos componentes não carcaças

\begin{tabular}{|c|c|c|c|c|c|}
\hline \multirow{2}{*}{ Variáveis, em kg } & \multicolumn{3}{|c|}{ Aditivos ${ }^{\ddagger}$} & \multirow{2}{*}{ Valor-P } & \multirow{2}{*}{$\mathrm{EPM}^{¥}$} \\
\hline & $\mathrm{CT}$ & $\mathrm{Zn}$ & $\mathrm{PG}$ & & \\
\hline \multicolumn{6}{|c|}{$\mathrm{SPCP}^{\#}$ e trato digestivo } \\
\hline Sangue & $1,10^{\mathrm{b}}$ & $1,54^{\mathrm{a}}$ & $1,12^{\mathrm{a}}$ & 0,022 & 0,067 \\
\hline Pele & 1,26 & 1,42 & 1,26 & 0,481 & 0,064 \\
\hline Cabeça & 1,40 & 1,50 & 1,49 & 0,524 & 0,037 \\
\hline Patas & 0,516 & 0,480 & 0,552 & 0,770 & 0,026 \\
\hline Trato gastrointestinal cheio & 9,22 & 9,32 & 8,51 & 0,390 & 0,273 \\
\hline Trato gastrointestinal vazio & 2,12 & 2,20 & 2,10 & 0,729 & 0,054 \\
\hline \multicolumn{6}{|c|}{ Órgãos vermelhos } \\
\hline Pulmão+traqueia & 0,427 & 0,383 & 0,467 & 0,402 & 0,023 \\
\hline Coração & 0,083 & 0,089 & 0,083 & 0,556 & 0,003 \\
\hline Fígado & 0,396 & 0,325 & 0,381 & 0,240 & 0,017 \\
\hline Rins & $0,082^{\mathrm{b}}$ & $0,106^{\mathrm{a}}$ & $0,095^{\mathrm{ab}}$ & 0,043 & 0,004 \\
\hline Baço & 0,031 & 0,032 & 0,034 & 0,906 & 0,002 \\
\hline Pâncreas & 0,025 & 0,027 & 0,024 & n.s. & 0,002 \\
\hline
\end{tabular}

${ }^{a}$ Médias na mesma linha seguidas por letras distintas são diferentes pelo teste de Tukey-Kramer $(\mathrm{P}<0,05)$.

${ }^{\ddagger} \mathrm{CT}=$ ausência de aditivo; $\mathrm{Zn}=$ adição de $\mathrm{ZnSO}_{4} \cdot 7 \mathrm{H}_{2} \mathrm{O}$ para fornecimento de $300 \mathrm{mg} \mathrm{Zn}$ dia ${ }^{-1}$ no sal; $\mathrm{PG}=$ adição de $2,5 \mathrm{ml} \mathrm{kgPC}{ }^{0,75-1}$ animal $^{-1} \mathrm{dia}^{-1}$ de propilenoglicol misturado ao concentrado. ${ }^{\sharp} \mathrm{EPM}=$ erro-padrão da média.

${ }^{\#} \mathrm{SPCP}=$ sangue, pele, cabeça e patas.

Tabela 7. Efeito do sulfato de zinco e do propilenoglicol em ovinos em pastagem nativa da Caatinga, no período chuvoso, nas características da carne

\begin{tabular}{|c|c|c|c|c|c|}
\hline \multirow{2}{*}{ Variáveis } & \multicolumn{3}{|c|}{ Aditivos } & \multirow{2}{*}{ Valor-P } & \multirow{2}{*}{$\mathrm{EPM}^{¥}$} \\
\hline & $\mathrm{CT}$ & $\mathrm{Zn}$ & PG & & \\
\hline \multicolumn{6}{|c|}{ Aspectos físicos } \\
\hline pH após 24 horas & 5,83 & 5,98 & 5,73 & 0,409 & 0,073 \\
\hline Capacidade de retenção de água (\%) & 54,9 & 58,8 & 60,7 & 0,099 & 1,15 \\
\hline Perda por cocção $(\%)$ & 53,6 & 53,9 & 54,3 & 0,970 & 0,698 \\
\hline Força de cisalhamento $\left(\mathrm{kgf} \mathrm{cm}^{2-1}\right)$ & 7,25 & 7,79 & 7,54 & 0,060 & 0,133 \\
\hline \multicolumn{6}{|c|}{ Aspectos químicos, \% } \\
\hline Umidade & 79,2 & 78,5 & 77,7 & 0,141 & 0,318 \\
\hline Cinzas & $0,911^{\mathrm{b}}$ & $1,15^{\mathrm{a}}$ & $0,921^{\mathrm{b}}$ & 0,036 & 0,035 \\
\hline Proteína & 27,0 & 26,6 & 28,9 & 0,138 & 0,460 \\
\hline Lipídios & 0,597 & 0,878 & 0,647 & 0,409 & 0,063 \\
\hline \multicolumn{6}{|c|}{ Atributos organolépticos ${ }^{\beta}$} \\
\hline Dureza & 4,04 & 3,52 & 3,87 & 0,755 & 0,285 \\
\hline Suculência & 4,77 & 4,25 & 4,26 & 0,629 & 0,250 \\
\hline Sabor & 4,78 & 4,14 & 4,39 & 0,512 & 0,227 \\
\hline Aroma & 3,49 & 3,59 & 3,42 & 0,959 & 0,246 \\
\hline Aceitação & 4,91 & 4,53 & 4,37 & 0,705 & 0,265 \\
\hline
\end{tabular}

${ }^{a}$ Médias na mesma linha seguidas por letras distintas são diferentes pelo teste de Tukey-Kramer $(\mathrm{P}<0,05)$ e ${ }^{\beta}$ KruskalWallis). ${ }^{\ddagger} \mathrm{CT}=$ sem aditivo; $\mathrm{Zn}=$ adição de $\mathrm{ZnSO}_{4} .7 \mathrm{H}_{2} \mathrm{O}$ para fornecimento de $300 \mathrm{mg} \mathrm{Zn}$ dia ${ }^{-1}$ no sal; $\mathrm{PG}=$ adição de $2,5 \mathrm{ml} \mathrm{kgPC}{ }^{0,75-1}$ animal $^{-1} \mathrm{dia}^{-1}$ de propilenoglicol misturado ao concentrado. ${ }^{*} \mathrm{EPM}=$ erro-padrão da média.

Os valores de CRA nos tratamentos apresentaram-se dentro dos parâmetros normais (Lawrie, 2005). Contudo, a PPC média foi elevada nos tratamentos em que foram fornecidos o sulfato de zinco e o propilenoglicol, e as condições da qualidade do pasto ao final da terminação não propiciaram adequado acabamento de carcaça e consequente teor de lipídios que contribuísse para menor perda de líquido durante a cocção.

A força de cisalhamento foi de 7,53kgf, apresentando aspecto de dureza. Em avaliações da textura da carne ovina (Cezar e Sousa, 2007), 
a força de cisalhamento pode ser classificada em maciez, maciez intermediária e aspecto de dureza, com valores de $2,27 \mathrm{kgf} / \mathrm{cm}^{2}, 2,28$ e $3,63 \mathrm{kgf} / \mathrm{cm}^{2}$, e acima de $3,63 \mathrm{kgf} / \mathrm{cm}^{2}$, respectivamente.

Vale ressaltar que a maioria dos estudos utilizando o sulfato de zinco como modulador da fermentação do rúmen foi realizada em condições in vitro, sendo incipientes resultados de desempenho com ovinos em pastejo, principalmente em condição próxima à realizada na presente pesquisa. De maneira semelhante ocorreu com o propilenoglicol, em que os estudos foram direcionados para verificar a eficácia deste em corrigir balanços energéticos negativos em animais leiteiros de alta produção por um curto período.

Por outro lado, ruminantes em livre pastejo são seletivos quanto à escolha do que consumir e, em geral, selecionam a dieta com melhor qualidade (elevada digestibilidade e teor de proteína e menos compostos secundários) do que a média da biomassa vegetal em oferta (Nutrient..., 2007). No período chuvoso, quando há maior oferta de massa forrageira constituída por uma variada quantidade de espécies, naturalmente ocorrem alterações na proporção e na qualidade dos constituintes dietéticos obtidos por ovinos em pastejo ao longo desse período, afetando negativamente o desempenho dos animais (Costa, 2016).

\section{CONCLUSÕES}

O zinco e o propilenoglicol não melhoram o desempenho e as características de carcaça de animais terminados em pastagem nativa da Caatinga. O baixo suprimento energético devido à má qualidade do pasto entre os meses de abril e junho contribui para ineficiência no aproveitamento dos constituintes proteicos, implicando em menor consumo e consequente diminuição do desempenho.

\section{REFERÊNCIAS}

ARAÚJO FILHO, J.A. Manejo pastoril sustentável da Caatinga. Recife: Projeto Dom Helder Câmara, 2013. 200p.

ARAÚJO FILHO, J.A. Manipulação da vegetação lenhosa da Caatinga para fins pastoris. Sobral, CE: Embrapa Ovinos e Caprinos, 1990. 18p. (Circular Técnica, n.11).
ARAÚJO, A.R. Composição botânica e qualidade do pasto selecionado por ovelhas em Caatinga raleada e enriquecida. 2015. 125f. Tese (Doutorado em Zootecnia) - Escola de Veterinária, Universidade Federal de Minas Gerais, Belo Horizonte, MG.

ARELOVICH, H.M.; OWENS, F.N.; HORN, G.W.; VIZCARRA, J.A. Effects of supplemental zinc and manganese on ruminal fermentation, forage intake, and digestion by cattle fed prairie hay and urea. $J$. Anim. Sci., v.78, p.2972-2979, 2000.

BANCO de dados meteorológicos para ensino e pesquisa (BDMEP) - dados históricos de Sobral, CE. Sobral: BDMEP, 2015. Disponível em: $<$ http://www.inmet.gov.br/portal/index.php?r=bdmep/ bdmep>. Acessado em: 06 de nov. 2015.

BRASIL. Ministério da Agricultura, do Abastecimento. Departamento de Inspeção de Produtos de Origem Animal - DIPOA. Divisão de Normas Técnicas. Decreto n.30,691, alterado pelos Decretos n. 1,255 de 25- 06-62, n. 1236 de 02-09-94, n.1.812 de 08-02-96 e n.2.244 de 04-06-97. Aprova o regulamento da inspeção industrial e sanitária de produtos de origem animal (RIISPOA). Lex: Diário Oficial da União de 5 de julho de 1997, seção I, p.11555. Brasília, 1997.

CEZAR, M.F.; SOUZA, W.H. Carcaças ovinas $e$ caprinas: obtenção, avaliação e classificação. Uberaba: Agropecuária Tropical, 2007. 147p.

COSTA, H.H.A. Caracterização florística da pastagem nativa da Caatinga e efeitos de aditivos sobre o consumo, emissão de metano e desempenho de ovinos. 2016. 109f. Tese (Doutorado em Zootecnia) Escola de Veterinária, Universidade Federal de Minas Gerais, Belo Horizonte, MG.

CUNHA, E.A.; BUENO, M.S.; SANTOS, L.E. et al. Desempenho e características de carcaça de cordeiros Suffolk alimentados com diferentes volumosos. Cienc. Rural, v.31, p.671-676, 2001.

CZERKAWISK, J.W.; BRECKERINDGE， G. Dissimilation of 1,2-propanediol by rumen microorganisms. Br. J. Nutr., v.29, p.317-330, 1973.

DANTAS, A.F.; PEREIRA FILHO, J.M.; SILVA, A.M.A. et al. Característica da carcaça de ovinos Santa Inês terminados em pastejo e submetidos a diferentes níveis de suplementação. Cienc. Agrotec., v.32, p.1280-1286, 2008

DUCKETT, S.K.; KLEIN, T.A.; DODSON, M.V.; SNOWDER, G.D. Tenderness of normal and callipyge lamb aged fresh or after freezing. Meat Sci., v.49, p.19-26, 1998.

ERYAVUZ, A.; DEHORITY, B.A. Effects of supplemental zinc concentration on cellulose digestion and cellulolytic and total bacterial numbers in vitro. Anim. Feed Sci. Technol., v.151, p.17-183, 2009. 
FOLCH, J.; LESS, M.; STANLEY, G.H.S. A simple method for the isolation and purification of total lipides from animal tissues. J. Biol. Chem., v.226, 497$509,1957$.

HATFIELD, R.D.; JUNG, H.G.; RALPH, J. et al. A comparison of the insoluble residues produced by the Klason lignin and acid detergent lignin procedures. $J$. Sci. Food Agric., v.65, p.51-58, 1994.

JAFARPOUR, N.; KHORVASH, M.; RAHMANI, H.R. et al. Dose-responses of zinc-methionine supplements on growth, blood metabolites and gastrointestinal development in sheep. J. Anim. Physiol. Anim. Nutr., v.99, p.668-675, 2015.

KIM, Y.K.; CHOI, H.; MYUNG, K.H. Effects of propylene glycol on carcass traits and its related gene expression in Korean native steers. J. Anim. Sci., v.83, p.344-349, 2005.

LARMOND, E. Laboratory methods for evaluation of foods. Ottawa: Food Research Institute, 1979. [104p.].

LAWRIE, R.A. Ciência da carne: constituição química e bioquímica do músculo. Porto Alegre: Artimed, 2005. p.79-120.

LICITRA, G.; HERNANDEZ, T.M.; VAN SOEST, P.J. Standardization of procedures for nitrogen fractionation of ruminant feeds. Anim. Feed Sci. Technol., v.57, p.347-358, 1996.

MINERAL tolerance of animals. 2.ed. Washington: National Academies Press, 2005. 510p.

NUTRIENT of small ruminants: sheep, goats, cervids, and new world camelids. Washington: National Academy Press, 2007. 384p.

OFFICIAL methods of analysis. 18.ed. Gaithersburg, Maryland: AOAC, 1990.

OLSON, K.C. Diet sample collection by esophageal fistula and rumen evacuation techniques. J. Range Manag., v.44, p.515-519, 1991.

OSÓRIO, J.C.S.; OSÓRIO, M.T.M.; JARDIM, P.O.C. (Eds.). Métodos para avaliação de carne ovina "in vivo" na carcaça e na carne. Pelotas: UFPEL, 1998. p.107.
PFISTER, J.A.; MALECHECK, J.C. The voluntary forage intake and nutrition of goats and sheep in the semi-arid tropics of northeastern Brazil. J. Anim. Sci., v.63, p.1078-1086, 1986.

SALIBA, E.O.S.; PILO-VELOSO, D.; RODRIGUEZ, N.M. et al. Characterization of lignin before and after exposure to the gastrointestinal tract of ruminants. $\mathrm{Am}$. J. Anal. Chem., v.7, p.748-753, 2016.

SENGER, C.C.D.; KOZLOSKI, G.V.; SANCHEZ, L.M.B. et al. Evaluation of autoclave procedures for fiber analysis in forage and concentrate feedstuffs. Anim. Feed Sci. Technol., v.146, p.169-174, 2008.

SIERRA, I. Producción de cordero joven y pesado en laraza v.18, p.28, 1973.

SILVA SOBRINHO, A.G. Criação de ovinos. Jaboticabal: Funep, 2001. 302p.

SILVA, N.L.; ARAÚJO FILHO, J.A.; SOUSA, F.B. Manipulação da vegetação da Caatinga para produção sustentável de forragem. Sobral, Ceará: Embrapa Ovinos e Caprinos, 2007. 11p. (Circular Técnica, n.34).

TILLEY, J.A.; TERRY, R.A. A two stage technique for the in vitro digestion of forage crops. J. Br. Grassl. Soc., v.18, p.104-111, 1963.

TSEGAY, T.; YOSEPH, M.; MENGISTU, U. Comparative evaluation of growth and carcass traits of indigenous and crossbred (Dorper $\times$ Indigenous) Ethiopian Sheep. Small Ruminant Res., v.114, p.247252,2013

VAN SOEST, P.J.; ROBERTSON, J.B.; LEWIS, B.A. Methods for dietary fiber, neutral detergent fiber, and nonstarch polysaccharides in relation to animal nutrition. J. Dairy Sci., v.74, p.3583-3597, 1991.

WALLACE, J.D.; HYDER, D.N.; VAN DYNE, G.M. Salivary contamination of forage selected by esophageal fistulated steers grazing sandhill grassland. J. Range Manag., v.25, p.184-187, 1972.

WHEELER, T.I.; SHACKEFORD, S.D.; KOOHMARAIE, M. Sampling, cooking and coring effects on Warner-Bratzler shear force values in beef. J. Anim. Sci., v.74, p.553-1562, 1996. 